\title{
Costs and effectiveness of a nurse specialist anticoagulant service
}

\author{
F C Taylor, A Gray, H Cohen, L Gaminara, M Ramsay, D Miller
}

\begin{abstract}
Department of Epidemiology and Public Health, Imperial College School of Medicine at St Mary's, London W2 1PG, UK

D Miller
\end{abstract}

Department of Haematology H Cohen

Health Economics Research Centre, Wolfson College, Linton Road, Oxford OX2 6UD, UK

A Gray

Department of Haematology, St Albans and Hemel Hempstead NHS Trust, St Albans AL3 9XX, UK

L Gaminara

Public Health Laboratory Service, CDSC, 61 Colindale Avenue, London NW9 5EQ, UK

M Ramsay

University

Department of

Psychiatry, Royal Free

Hospital School of Medicine, Rowland Hill Street, London NW3 2PF, UK

F C Taylor

Correspondence to: F C Taylor.

Accepted for publication 15 July 1997

\begin{abstract}
Aims-To determine the costs and effectiveness of an anticoagulant nurse specialist service compared with a conventional consultant service based on two hospital sites in northwest Hertfordshire.

Methods-Sequential design comparing retrospectively the conduct and outcomes of a consultant service with a nurse specialist service over two six month periods. In each of the six month study periods, all new patients consecutively referred for anticoagulation over a three month period (group A) at the start of each study period and a random selection of patients who had already been attending the anticoagulant service for one year or more (group B) were included in the study. Group A patients were followed for up to three months and group $B$ patients for six months. The main outcome measures were costs of service provision and effectiveness. Costs included those for the use of the anticoagulant service, those related to general practitioner (GP) visits and hospitalisations, and running costs (staff time, laboratory tests, patient transport). Measures of effectiveness were the mean proportion of time patients spend in the therapeutic range, the number of drugs being taken that could interact adversely and/or inhibit haemostatic function, and patient and GP satisfaction with service provision.
\end{abstract}

Results-In the consultant service, for group $A$ there were more patients aged 66-75 years $(p=0.004)$ and fewer patients aged more than 76 years $(p=0.001)$; and for group $B$, there were fewer patients on anticoagulation for cardiac conditions $(p=0.001)$, but more on anticoagulation for thromboembolic conditions $(p=0.02)$ than in the nurse specialist service. The clinic running costs of the nurse specialist service were $£ 4.99$ per attendance, compared with $£ 4.75$ in the consultant service. Including all other costs related to treatment, there was no statistically significant difference in cost per patient. There was no significant difference in the proportion of time patients spent in the therapeutic range between the consultant service and the nurse specialist service. In the nurse specialist service, fewer patients in group A were taking drugs that could interact adversely and/or inhibit haemostatic function $(p=0.01)$ and more patients were satisfied with service provision $(p=0.04)$ compared with the consultant service. There was no significant variation in GP satisfaction between the two services.

Conclusion-In the provision of outpatient anticoagulation, the nurse specialist service was no more expensive than the consultant service and, using our primary outcome, at least as effective. The nurse specialist service has some clear advantages compared to the consultant service: provision of domicilliary care for housebound patients, fewer new patients taking drugs that could interact adversely and/or inhibit haemostatic function patients, it is preferred by newly referred patients to the consultant service, and it is acceptable to their GPs.

(F Clin Pathol 1997;50:823-828)

Keywords: costs; nurses; anticoagulation

Life long anticoagulation treatment has been shown to be cost effective for patients at risk from thromboembolic conditions provided the risks of bleeding are kept low. ${ }^{1}$ Following evidence of clinical benefit from anticoagulation in-for example, non-rheumatic atrial fibrillation, the use of anticoagulation has been increasing. ${ }^{2}$ Recently, the annual increase in numbers of patients referred to anticoagulant clinics in the UK for life long treatment has been estimated as ranging from $6 \%$ to $25 \% .^{23}$

Warfarin treatment, however, is potentially dangerous: life threatening complications such as bleeding may occur with over anticoagulation and thromboembolism with under anticoagulation. ${ }^{4}$ The therapeutic range for the international normalised ratio (INR) is narrow and the risk of adverse events is related directly to the adequacy of therapeutic control, ${ }^{4}$ which can be compromised by external factors including intercurrent illness and concurrent drugs. $^{5}$ Thus, maintaining patients on treatment safely can create problems. ${ }^{6}$

Safe levels of anticoagulation are considered to be achieved if patients are maintained in the INR range $70 \%$ of the time $^{7}$ but there is evidence in the UK to suggest that this is often not attained. ${ }^{8}$ Reasons contributing to this suboptimal control include patient management often being left to inexperienced and rotating junior doctors ${ }^{10}$ and the presence of inadequate administrative systems. ${ }^{11}$ Computer dosing systems ${ }^{8}$ and general practitioner (GP) ${ }^{9}$ or pharmacist ${ }^{2}$ managed anticoagulant clinics have so far had varying success in satisfactory anticoagulant control. To achieve 
maximal benefit with minimal risks to patients, a high quality anticoagulant service is essential. The increasing demand necessitates an urgent review of current service provision and exploration of alternative models, their costs, and effectiveness in terms of defined outcomes.

Studies on anticoagulant nurse specialists in the USA have consistently reported advantages: better anticoagulant control, fewer drugs taken by patients that might interact adversely and/or inhibit haemostatic function, and higher patient satisfaction rates. ${ }^{12-14}$ There has, to date, been limited evidence published in the UK of the consequences of devolving management of anticoagulation to nurse specialist anticoagulant clinics, ${ }^{15}$ despite nurse specialists sharing in the provision of health care for other chronic medical conditions. ${ }^{16}{ }^{17}$ We present the results of an evaluation of the costs and effectiveness of a nurse specialist anticoagulant service. More specific details on the adequacy of haematological management of this study are reported elsewhere. ${ }^{18}$

\section{Methods}

DESIGN AND SUBJECTS

A sequential design was used in which data were collected on a consultant service over a six month period, followed by observations on a nurse specialist service over a similar period. Stable anticoagulation is normally achieved within the first three months of treatment and we followed the example of other investigators in identifying two groups of patients and two follow up periods. ${ }^{19-21}$ Group A were consecutive patients, newly referred to the anticoagulant clinic, identified from the weekly clinic lists, and followed up for up to three months from the start of each study period; group B comprised a random selection of patients identified from the computer dosing system who had been attending the anticoagulant clinic for a period of one year or more and who were followed up for each of the six month periods.

\section{SERVICE PROVISION}

The anticoagulant service in northwest Hertfordshire is based on two hospital sites and is managed by two consultant haematologists. The service is aided by a computer dosing system and patients are given dosing instructions by post, or if necessary, by telephone. Patients seen for consultation include those who are newly referred (until stabilised), whose INR values are persistently out of therapeutic range, or who request specialist advice. The twice weekly consultant service was conducted by two consultant haematologists. For the nurse specialist service, two nurses were trained over a three month period in specific aspects of anticoagulant care including lectures in haematology, pharmacology, laboratory techniques, and administration. Training was provided by specialist staff at the study site and a consultant haematologist with expertise in anticoagulation based at a London teaching hospital. The nurse specialist service was introduced in place of the consultant service but remained under the general supervision of the two consultant hae- matologists. It included the introduction of a revised administrative system and a domiciliary service for housebound patients.

costs

All resources associated with starting and running the service and with the treatment were quantified and unit costs were applied to obtain a total cost for each measure of outcome. Data were obtained from the hospital finance department for the unit costs of blood tests, hospitalisations related to anticoagulant treatment, clinic staff, hospital transport, and domiciliary nurse visits; from national figures for GP consultations related to anticoagulant treatment; and from the British National Formulary for therapeutic agents. Clinic cost calculations were based on volume of staff inputs and the midpoint of the relevant salary range, including employment costs. All costs were based on 1995 prices. Costs to patients such as travel costs and time off work were excluded because these would have been difficult to estimate and are unlikely to differ materially between the two services. Costs of premises used were also excluded as the accommodation remained unchanged for each service. Previous studies report hospitalisation rates for major events related to anticoagulation at $0.002-0.005$ per patient per treatment month. ${ }^{9} 1022$ We included these costs in our calculations, costed on the basis of length of stay and speciality cost per inpatient day. For the nurse specialist service, training costs were calculated, based on the recorded time of teaching inputs to training, discounted at $6 \%$ over the expected mean time in service of a nurse specialist, which was estimated as five years. ${ }^{23}$

\section{MEASURES OF EFFECTIVENESS}

Primary outcome measure

The mean proportion of time that patients spend in the therapeutic range. Control of anticoagulation was evaluated against the patient's individual INR target range. The time each patient spent within their therapeutic range was estimated by calculating the time interval between INR tests and dividing it equally between INR results at the beginning and end of each interval. ${ }^{21} \mathrm{~A}$ validated proforma $^{24}$ was used to obtain data from anticoagulant record cards and the computer dosing system.

\section{Secondary outcome measures}

Number of GP consultations and inpatient episodes arising from adverse events related to anticoagulant treatment; number of drugs being taken that could interact adversely and/or inhibit haemostatic function; patient and GP satisfaction with both services. Data were obtained by sending all patients recruited to the study a previously tested and validated questionnaire which included questions on satisfaction with anticoagulant clinic provision. ${ }^{24}$ Patient reports of inpatient episodes were validated against hospital case notes and/or written confirmation from the patient's GP. A questionnaire was used to obtain data on GP satisfaction with both services. As 
Table 1 Study population

\begin{tabular}{|c|c|c|c|c|c|c|}
\hline & \multicolumn{3}{|l|}{ Group $A$} & \multicolumn{3}{|l|}{ Group B } \\
\hline & $C A S$ & NSAS & $p$ value & $C A S$ & $N S A S$ & $p$ value \\
\hline Number* & $100(86 \%)$ & $106(85 \%)$ & 0.98 & $111(90 \%)$ & $113(87 \%)$ & 0.51 \\
\hline Male & $50(50 \%)$ & $56(53 \%)$ & 0.79 & $67(60 \%)$ & $66(58 \%)$ & 0.87 \\
\hline Female & $50(50 \%)$ & $50(47 \%)$ & 0.79 & $44(40 \%)$ & $47(42 \%)$ & 0.87 \\
\hline-45 years & $16(16 \%)$ & $10(9 \%)$ & 0.22 & $6(5 \%)$ & $10(9 \%)$ & 0.45 \\
\hline $46-65$ years & $30(30 \%)$ & $35(33 \%)$ & 0.75 & $37(34 \%)$ & $45(40 \%)$ & 0.38 \\
\hline $66-75$ years & $43(43 \%)$ & $23(22 \%)$ & 0.004 & $48(43 \%)$ & $43(38 \%)$ & 0.51 \\
\hline 75 - years & $11(11 \%)$ & $38(36 \%)$ & 0.001 & $20(18 \%)$ & $15(13 \%)$ & 0.27 \\
\hline Mean age (years) & 63 & 66 & & 67 & 64 & \\
\hline Venous thromboembolism & $56(56 \%)$ & $55(52 \%)$ & 0.65 & $36(32 \%)$ & $20(18 \%)$ & 0.02 \\
\hline Cardiac condition & $40(40 \%)$ & $50(47 \%)$ & 0.37 & $72(65 \%)$ & $93(82 \%)$ & 0.001 \\
\hline Other & $4(4 \%)$ & $1(1 \%)$ & ND & $3(3 \%)$ & - & ND \\
\hline
\end{tabular}

^Percentage of patients replying to the questionnaire. CAS, consultant service; NSAS, nurse specialist service.

communications with general practice about anticoagulation is more likely to be at the start of treatment, GPs of all group A patients were recruited to the study.

\section{STATISTICAL ANALYSIS}

Statistical analysis was confined to patients whose anticoagulant records were available and who responded to the questionnaire. Confidence intervals, $\chi^{2}$, and $t$ test for means were used to test differences between the two services for statistical significance.

\section{Results}

STUDY POPULATION

There were no significant differences between the study populations in groups A and B.

\section{COST DATA}

In evaluating the cost data, a cost minimisation approach was adopted because the outcomes were similar in the two services. ${ }^{25}$ Clinic running costs per week for the consultant service were $£ 729$, with a mean cost per attendance of $£ 4.75$. This compared with a higher running cost for the nurse specialist service at $£ 807$, but the number of attendances also increased (by $6 \%$ ), so that the resulting mean cost per attendance only rose to $£ 4.99$. The higher running cost of the nurse specialist service clinics reflect longer clinic hours practised by the nurse specialists compared with the hospital consultants, and the continued input of consultant supervision time amounting to a mean of 30 minutes per week.

\section{RESPONSE RATES}

In group A, 100 of 116 (86\%) patients in the consultant service and 106 of $124(85 \%)$ in the nurse specialist service responded to the questionnaire. In group B, 111 of $122(90 \%)$ in the consultant service and 113 of $129(87 \%)$ in the nurse specialist service responded to the questionnaire. For all patients responding to the questionnaire, anticoagulant case records and information on the computer dosing system were available.

GROUP A

The mean follow up period for new patients of the two services was five weeks. In the consultant service there were more patients aged 66-75 years $(p=0.004)$ and a corresponding deficit of patients aged more than 76 years compared with the nurse specialist service $(p=0.001)$ (table 1$)$. The volume of resources used was similar for the two services, except for the consequences of introducing the domiciliary service and the hospitalisation

Table 2 Volume and costs of resources used per patient in group $A$ over the three month study period

\begin{tabular}{|c|c|c|c|c|c|c|c|}
\hline & \multirow[b]{2}{*}{ Service } & \multicolumn{2}{|c|}{ Volume of resources } & \multicolumn{2}{|c|}{ Cost of resources } & \multirow[b]{2}{*}{$\begin{array}{l}\text { Mean } \\
\text { difference }\end{array}$} & \multirow[b]{2}{*}{$\begin{array}{l}95 \% \text { confidence } \\
\text { intervals }\end{array}$} \\
\hline & & $\begin{array}{l}\text { Mean number } \\
\text { of items }\end{array}$ & $\begin{array}{l}\text { Standard error } \\
\text { mean }\end{array}$ & Mean cost & $\begin{array}{l}\text { Standard error } \\
\text { mean }\end{array}$ & & \\
\hline \multirow[t]{2}{*}{ Blood tests (reagents and equipment) } & CAS & 4.0 & 0.18 & 0.9 & 0.04 & \multirow[t]{2}{*}{0.02} & \multirow[t]{2}{*}{-0.1 to 0.14} \\
\hline & NSAS & 3.9 & 0.23 & 0.8 & 0.05 & & \\
\hline \multirow[t]{2}{*}{ Clinic visits (including staff costs) } & CAS & 4.0 & 0.18 & 19.1 & 0.84 & \multirow[t]{2}{*}{-0.51} & \multirow[t]{2}{*}{-3.31 to 2.28} \\
\hline & NSAS & 3.9 & 0.23 & 19.7 & 1.14 & & \\
\hline \multirow[t]{2}{*}{ Transport visits } & CAS & 0.5 & 0.13 & 6.2 & 1.76 & \multirow[t]{2}{*}{3.04} & \multirow[t]{2}{*}{-1.41 to 7.49} \\
\hline & NSAS & 0.2 & 0.1 & 3.2 & 1.41 & & \\
\hline \multirow[t]{2}{*}{ Domiciliary visits } & CAS & 0.0 & 0.0 & 0.0 & 0.0 & \multirow[t]{2}{*}{-4.36} & \multirow[t]{2}{*}{-7.71 to -1.02} \\
\hline & NSAS & 0.3 & 0.12 & 4.4 & 1.68 & & \\
\hline \multirow[t]{2}{*}{ Related GP visits } & CAS & 0.2 & 0.05 & 3.3 & 0.77 & \multirow[t]{2}{*}{-2.15} & \multirow[t]{2}{*}{-4.71 to 0.4} \\
\hline & NSAS & 0.3 & 0.07 & 5.4 & 1.04 & & \\
\hline \multirow{4}{*}{$\begin{array}{l}\text { Drugs that may adversely interact } \\
\text { and/or inhibit haemostatic function } \\
\text { Treatment days }\end{array}$} & CAS & 3.0 & 0.22 & 12.19 & 0.92 & \multirow[t]{2}{*}{0.42} & \multirow[t]{2}{*}{-2.15 to 2.98} \\
\hline & NSAS & 2.8 & 0.22 & 11.8 & 0.92 & & \\
\hline & CAS & 41.0 & 2.71 & - & - & - & - \\
\hline & NSAS & 35.7 & 2.62 & - & - & & \\
\hline \multirow[t]{2}{*}{ Related hospitalisation } & CAS & 0.0 & 0.0 & 0.0 & 0.0 & \multirow[t]{2}{*}{-7.44} & \multirow[t]{2}{*}{-22.2 to 7.32} \\
\hline & NSAS & 0.0 & 0.01 & 7.4 & 7.44 & & \\
\hline Total cost: CAS & & - & - & 42.2 & 2.27 & -3.49 & -10.89 to 3.91 \\
\hline \multicolumn{8}{|l|}{ Total cost: NSAS without } \\
\hline hospitalisation cost & & - & - & 45.7 & 2.99 & & \\
\hline \multicolumn{8}{|l|}{ Total cost: NSAS with hospitalisation } \\
\hline cost & & - & - & 53.1 & 8.59 & -10.94 & -28.53 to 6.66 \\
\hline \multirow[t]{2}{*}{ Log transformed total cost } & CAS & - & - & 3.6 & 0.05 & & \\
\hline & NSAS & - & - & 3.65 & 0.07 & -0.04 & -0.21 to 0.12 \\
\hline
\end{tabular}

Prices in pounds sterling, 1995 prices. 
Table 3 Volume and costs of resources used per patient in group $B$ over the six month study period

\begin{tabular}{|c|c|c|c|c|c|c|c|}
\hline & \multirow[b]{2}{*}{ Service } & \multicolumn{2}{|c|}{ Volume of resources } & \multicolumn{2}{|c|}{ Cost of resources } & \multirow[b]{2}{*}{$\begin{array}{l}\text { Mean } \\
\text { difference }\end{array}$} & \multirow[b]{2}{*}{$\begin{array}{l}95 \% \text { confidence } \\
\text { intervals }\end{array}$} \\
\hline & & $\begin{array}{l}\text { Mean number } \\
\text { of items }\end{array}$ & $\begin{array}{l}\text { Standard error } \\
\text { mean }\end{array}$ & Mean cost & $\begin{array}{l}\text { Standard error } \\
\text { mean }\end{array}$ & & \\
\hline \multirow[t]{2}{*}{ Blood tests (reagents and equipment) } & CAS & 5.2 & 0.23 & 1.1 & 0.05 & \multirow[t]{2}{*}{0.06} & \multirow[t]{2}{*}{-0.07 to 0.20} \\
\hline & NSAS & 4.9 & 0.24 & 1.03 & 0.05 & & \\
\hline \multirow[t]{2}{*}{ Clinic visits (including staff costs) } & CAS & 5.2 & 0.23 & 24.8 & 1.1 & \multirow[t]{2}{*}{0.23} & \multirow[t]{2}{*}{-2.96 to 3.43} \\
\hline & NSAS & 4.9 & 0.24 & 24.6 & 1.2 & & \\
\hline \multirow[t]{2}{*}{ Transport visits } & CAS & 0.4 & 0.14 & 4.8 & 1.4 & \multirow[t]{2}{*}{2.60} & \multirow[t]{2}{*}{-1.77 to 6.97} \\
\hline & NSAS & 0.2 & 0.09 & 2.2 & 1.2 & & \\
\hline \multirow[t]{2}{*}{ Domiciliary visits } & CAS & 0.0 & 0.0 & 0.0 & 0.0 & \multirow[t]{2}{*}{-0.62} & \multirow[t]{2}{*}{-1.85 to 0.61} \\
\hline & NSAS & 0.0 & 0.04 & 0.6 & 0.6 & & \\
\hline \multirow[t]{2}{*}{ Related GP visits } & CAS & 0.4 & 0.06 & 6.1 & 1.0 & \multirow[t]{2}{*}{1.62} & \multirow[t]{2}{*}{-0.90 to 4.13} \\
\hline & NSAS & 0.3 & 0.05 & 4.5 & 0.8 & & \\
\hline \multirow{4}{*}{$\begin{array}{l}\text { Drugs that may adversely interact } \\
\text { and/or inhibit haemostatic function } \\
\text { Related hospitalisations }\end{array}$} & CAS & 3.1 & 0.19 & 12.8 & 0.8 & \multirow[t]{2}{*}{-1.68} & \multirow[t]{2}{*}{-3.99 to 0.64} \\
\hline & NSAS & 3.5 & 0.21 & 14.5 & 0.9 & & \\
\hline & CAS & 0.0 & 0.0 & 0.0 & 0.0 & \multirow[t]{2}{*}{-5.93} & \multirow[t]{2}{*}{-17.68 to 5.82} \\
\hline & NSAS & 0.0 & 0.01 & 5.9 & 5.9 & & \\
\hline Total cost: CAS & & - & - & 49.7 & 2.8 & -2.22 & -5.09 to 9.54 \\
\hline \multicolumn{8}{|l|}{ Total cost: NSAS without } \\
\hline hospitalisation cost & & - & - & 47.4 & 2.4 & & \\
\hline \multirow{2}{*}{\multicolumn{8}{|c|}{$\begin{array}{l}\text { Total cost: NSAS with hospitalisation } \\
\text { cost }\end{array}$}} \\
\hline & & - & - & 53.4 & 7.0 & \multirow[t]{2}{*}{-3.71} & \multirow[t]{2}{*}{-18.54 to 11.12} \\
\hline \multirow[t]{2}{*}{ Log transformed log total cost } & CAS & - & - & 3.8 & 0.05 & & \\
\hline & NSAS & - & - & 3.7 & 0.05 & -0.02 & -0.13 to 0.17 \\
\hline
\end{tabular}

Prices in pounds sterling, 1995 prices.

Table 4 Time spent in therapeutic range and mean interval between INR tests

\begin{tabular}{|c|c|c|c|c|c|c|c|c|c|c|}
\hline & \multicolumn{5}{|c|}{ Group $A$ (excludes new attenders) } & \multicolumn{5}{|l|}{ Group B } \\
\hline & $\begin{array}{l}C A S \\
(n=93)\end{array}$ & $\begin{array}{l}\text { NSAS } \\
(n=95)\end{array}$ & $\begin{array}{l}\text { Mean } \\
\text { diff }\end{array}$ & $\begin{array}{l}\text { Standard } \\
\text { deviation }\end{array}$ & $p$ value & $\begin{array}{l}C A S \\
(n=111)\end{array}$ & $\begin{array}{l}\text { NSAS } \\
(n=113)\end{array}$ & $\begin{array}{l}\text { Mean } \\
\text { diff }\end{array}$ & $\begin{array}{l}\text { Standard } \\
\text { deviation }\end{array}$ & $p$ value \\
\hline \multicolumn{11}{|c|}{ Proportion of time patients spend } \\
\hline Within INR range & $58 \%$ & $61 \%$ & 1.46 & $\begin{array}{l}22.2 \text { CAS } \\
21.3 \text { NSAS }\end{array}$ & 0.65 & $73 \%$ & $74 \%$ & 8.5 & $\begin{array}{l}\text { 37.8 CAS } \\
\text { 39.4 NSAS }\end{array}$ & 0.09 \\
\hline Above INR range & $19 \%$ & $16 \%$ & 2.14 & $\begin{array}{l}\text { 10.6 CAS } \\
8.5 \mathrm{NSAS}\end{array}$ & 0.13 & $14 \%$ & $14 \%$ & 0.9 & $\begin{array}{l}25.3 \text { CAS } \\
24.1 \text { NSAS }\end{array}$ & 0.77 \\
\hline Below INR range & $23 \%$ & $23 \%$ & 0.7 & $\begin{array}{l}\text { 12.9 CAS } \\
11.5 \text { NSAS }\end{array}$ & 0.71 & $13 \%$ & $12 \%$ & 2.6 & $\begin{array}{l}\text { 23.7 CAS } \\
\text { 22.1 NSAS }\end{array}$ & 0.39 \\
\hline $\begin{array}{l}\text { Mean interval between } \\
\text { INR tests in days }\end{array}$ & 10.3 & 9.3 & - & 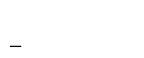 & 0.96 & 27.3 & 26.6 & - & 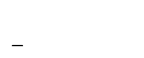 & 0.36 \\
\hline
\end{tabular}

Mean diff, mean difference.

Table 5 Secondary measures of effectiveness for patients in groups $A$ and $B$

\begin{tabular}{|c|c|c|c|c|c|c|}
\hline \multirow[b]{2}{*}{ Number of patients } & \multicolumn{3}{|l|}{ Group $A$} & \multicolumn{3}{|l|}{ Group B } \\
\hline & $\begin{array}{l}C A S \\
(n=100)\end{array}$ & $\begin{array}{l}\text { NSAS } \\
(n=106)\end{array}$ & $p$ value & $\begin{array}{l}C A S \\
(n=111)\end{array}$ & $\begin{array}{l}\text { NSAS } \\
(n=113)\end{array}$ & $p$ value \\
\hline $\begin{array}{l}\text { Taking drugs that may interact and/or } \\
\text { inhibit haemostatic function }\end{array}$ & $24 / 93(26 \%)$ & $10 / 94(11 \%)$ & 0.01 & $26 / 111(23 \%)$ & $17 / 113(15 \%)$ & 0.15 \\
\hline Visiting GPs for related events & $16 / 93(17 \%)$ & $22 / 94(23 \%)$ & 0.38 & $34 / 111(31 \%)$ & $28 / 113(25 \%)$ & 0.4 \\
\hline Admitted for related hospitalisations & $0 / 93(0 \%)$ & $1 / 94(1 \%)$ & ND & $0 / 114(0 \%)$ & $1 / 113(1 \%)$ & ND \\
\hline Satisfied with service provision ${ }^{\star}$ & $75 / 86(87 \%)$ & $87 / 91(96 \%)$ & 0.04 & $93 / 103(90 \%)$ & $106 / 110(96 \%)$ & 0.13 \\
\hline
\end{tabular}

$\star$ Excludes missing values.

which occurred in the nurse specialist service. Owing to the skewness of the results, the total costs per patient were log transformed and reanalysed. There was no statistical difference in the log total costs per patient $(\mathrm{p}=0.615)$ (table 2).

GROUP B

In the consultant service, there were fewer patients on anticoagulation for cardiac conditions $(p=0.001)$ but more on anticoagulation for thromboembolic conditions $(p=0.02)$ (table 1). Again, no significant difference between the two services in volume and costs of resources used was apparent, except for a single related hospitalisation under the nurse specialist service. Owing to the skewness of the results, the total costs per patient were log transformed and reanalysed and there was no statistical differences in the log total costs per patient $(\mathrm{p}=0.319)($ table 3$)$.

\section{SENSITIVITY ANALYSIS}

The cost of transport and domicilliary visits, and staffing costs were all increased and decreased by $15 \%$ in a sensitivity analysis. In all cases, any cost differences between the two groups remained non-significant.

\section{MEASURES OF EFFECTIVENESS}

For both groups $\mathrm{A}$ and $\mathrm{B}$, the mean proportion of time spent by patients in the therapeutic INR range was similar for each of the two services (table 4). In group A, fewer patients in the nurse specialist service were taking drugs that might interact and/or inhibit haemostatic function $(p=0.01)$ and a greater proportion of patients were satisfied with the service 
$(p=0.04)$ (table 5). Under the consultant service, 54 of $65(83 \%)$ GPs responded to the questionnaire compared with 61 of 81 (75\%) under the nurse specialist service. There was no significant difference in GP satisfaction between the two services.

\section{Discussion}

The aim of this study was to compare the costs and effectiveness of a nurse specialist anticoagulant service with that of a consultant service. Since there was no statistical difference between the two services in our primary outcome measure (mean proportion of time spent in therapeutic range) in either group, the cost data were presented in the form of a cost minimisation analysis in which the outcomes of both services were treated as similar. ${ }^{25}$

The study design was constrained by theoretical and practical considerations. Ideally, the evaluation of any intervention requires a randomised intervention/control design in a large number of test sites, which was not a practical option for the comparison of these two services. Comparison between services in only a small number of sites could have been misleading because of potential unknown differences in the study populations, in the structures and procedures in different clinics, and possibly other undefined confounding variables. A design comparing groups of patients managed in the same clinic in parallel but under different personnel posed operational problems and risked contamination between groups operating different systems alongside each other. We opted, therefore, for a sequential design.

Our results showed no significant differences in volume and costs of resources used by patients between the two services. In terms of safety, using our primary outcome measure, the nurse specialist service was as safe as the consultant service. The mean time that patients spent in therapeutic range for both groups is similar to other published results. ${ }^{212627}$ Using our secondary outcome measures for patients in group $\mathrm{A}$, there were significant advantages to the nurse specialist service compared with the consultant service. Fewer patients in the nurse specialist service were taking drugs that might interact and/or inhibit haemostatic function and a greater proportion of patients were satisfied with the service. This is in accordance with published results of studies from the USA on anticoagulant nurse specialists. ${ }^{12-14}$ In addition, the nurse specialist service was as acceptable to GPs as the consultant service. For patients in group B, there were no significant variations in the secondary measures of effectiveness but this may be due to the following: patients seen for consultation are either newly referred (until stabilised), have INR values which are persistently out of therapeutic range, or request specialist advice. Our results show that patients in group B remained within the therapeutic range $73-74 \%$ of time and that the mean interval between visits was 27 days, compared with 9-10 days for patients in group A. This would indicate that patients in group B would have less contact with the nurse specialists than patients in group A and, therefore, less opportunity to receive counselling and advice on treatment.

The slightly higher running cost of the nurse specialist service included the cost of the nurse specialist training programme. It would be anticipated that an expansion of nurse specialist services in time would create a stock of trained nurses and, hence, training costs would be reduced for individual hospital clinics recruiting staff.

The slightly higher costs of resources in group A for the nurse specialist service is accounted for by the greater number of GP consultations and one hospitalisation related to anticoagulant treatment. The (non-significant) increase in GP consultations may be explained by the fact that the nurse specialists were instructed to refer patients with events related to anticoagulant treatment to their GP to ensure safe monitoring. Unfortunately, detailed data on the reasons for consultations were not available but this would merit further investigation, particularly as the increase in GP consultations was not seen in group $B$. The absence of any treatment related hospitalisation under the consultant service was exceptional, but the period of observation was relatively short. The one hospitalisation in patients managed by the nurse specialist service was a 60 year old woman admitted for postmenopausal bleeding who, before admission, had been bleeding for a period of three weeks. This hospitalisation was probably unavoidable and not attributable specifically to any defect in the quality of anticoagulant control.

The higher cost of resources in group B for the nurse specialist service was also attributable to a single hospitalisation. This related to a 70 year old man who was admitted for bilateral haemorrhagic thalamic infarcts while on holiday. This hospitalisation may have been avoidable, but it is doubtful that the management of the case would have been different under the consultant service.

\section{CONCLUSION}

We conclude that the provision of outpatient anticoagulation by the nurse specialist service was not a more expensive option than the consultant service despite the introduction of a domicilliary service, the training costs of the nurse specialists, and longer anticoagulant clinic hours in the nurse specialist service. Using our primary outcome measure, the nurse specialist service was as safe as the consultant service. The nurse specialist service had some clear advantages compared to the consultant service, particularly for patients in group A. Fewer patients in the nurse specialist service were taking drugs that might may interact and/or inhibit haemostatic function and a greater proportion of patients were satisfied with the service. In addition, the nurse specialist service was as acceptable to GPs as the consultant service. We believe the nurse specialist service to be a viable alternative model of anticoagulant service provision in light of the increasing numbers of patients 
being referred for life long treatment. The results may have lessons for monitoring the care of patients with other chronic diseases.

We thank North Thames Regional Development Programme Primary/Secondary Care Interface for funding this study.

1 Gustaffson C, Asplund K Britton M, Norving B, Olsson B, Marke L. Cost effectiveness of primary stroke prevention in
atrial fibrillation: a Swedish perspective. $B M \mathcal{F}$ atrial fibrillation:

2 Radley A. Evaluation of anticoagulant control in a pharmacist operated anticoagulant clinic. $\mathcal{F}$ Clin Pathol 1995;48 454-7.

3 Taylor F, Corner J, Grant M, Adams D, Cohen H. Life-long anticoagulation with atrial fibrillation in the prevention of risk from stroke: Quantitative analysis of new referrals to an anticoagulant clinic. Cerebrovasc Dis 1996;6:146.

4 Ansell J. Oral anticoagulant therapy-50 years later. Arch Intern Med 1993;305:586-97.

5 Loken S, Shioshita G. Factors that influence therapeutic anticoagulation control. Nurse Practitioner Forum 1992;3: 95-102.

6 Fihn S, McDannell M, Donald M, Hanifekk J, Vermes D, Kent D, et al for the Warfarin Optimized Outpatien Follow-up Study Group. Risk factors for complications of chronic anticoagulation. Ann Intern Med 1993;118:51 1-20.

7 Besselaar A for the Control of Anticoagulation Subcommittee of the Scientific and Standardization Committee of the International Society on Thrombosis and Haemostasis. Recommended method for reporting therapeutic control of oral anticoagulant therapy. Thromb Haemost 1990;63:31617.

8 Poller L, Wright D, Rowlands M. Prospective comparative study of computer programmes used for management of warfarin. F Clin Pathol 1993;46:299-303.

9 Pell J, McIver B, Stuart P, Malone D, Alcock J. Comparison of anticoagulant control among patients attending general practice and a hospital anticoagulant clinic. Br ₹ Gen Prac practice and a hos

10 Shafi M, Mayberry J, Calcraft B. An audit of a medical anticoagulant clinic in a district general hospital. Postgrad Med f 1983;59:492-4

11 McInnes G, Helenglass G. The performance of clinics for outpatient control of anticoagulation. $\mathcal{F} R$ Coll Physician Lond 1987;21:42-5.
12 Wyness A. Evaluation of an educational programme for patients taking warfarin. $\mathcal{F}$ Adv Nurs 1990;15:1052-63.

13 Kornblitt P, Senderoff J, Davis-Erikson M, Zenk J Anticoagulant therapy: patient management and evaluation of an outpatient clinic. Nurse Pract 1990;15:21-32.

14 Seabrook G, Karp D, Smith D, Bandyk D, Towne J. An outpatient anticoagulation protocol managed by a vascular nurse clinician. Am f Surg 1990;160:501-5.

15 Van De Pette J, Mackie C. Clinics led by nurse practitioners can work well [letter]. BMf 1996;312:1226.

16 Newton V. Care in pre-admission clinics. Nursing Times 1996;92:27-8.

17 Baradell J. Cost-effectiveness and quality of care provided by clinical nurse specialists. 7 Psychs Nurs 1994;32:21-4.

18 Taylor F, Gaminara L, Cohen H, Ramsay M, Miller D. Evaluation of a nurse specialist anticoagulant service. Clinical Laboratory Haematol. [In press]

19 Copplestone A, Roath S. Assessment of therapeutic control of anticoagulation. Acta Haematol 1984;71:376-80.

20 Duxbury B. Therapeutic control of anticoagulant treatment. BMF 1982;284:702-4

21 Taylor F, Ramsay M, Renton A, Cohen H. Methods for managing the increased workload in anticoagulant clinics [letter]. BMF 1996;312:286.

22 Colwell N, O'Neill T, Tyrrell J, Robinson K, Clarke R, Graham I. An evaluation of an anticoagulant clinic. Int Med $\mathcal{F}$ 1990;83:94-7.

23 Gray A, Phillips V. Turnover, age and length of service: a comparison of nurses and other staff in the NHS. $\mathcal{F} A d v$ Nurs 1994;19:819-27.

24 Royal College of Physicians. Audit measures for good practice in anticoagulation therapy. Prepared by the Research Unit of the Royal College of Physicians. Taylor FC, J Gabbay, Tan $\mathrm{G}$, Cohen $\mathrm{H}$ in collaboration with the BCSH Haemostasis and Thrombosis Task Force of the British Society for Haeand Thrombosis Task Force of the British Society for

25 Drummond M, Stoddart G, Torrance G. Methods for the economic evaluation of health care programmes. Oxford: Oxford Medical Publications, 1995.

26 Vadher B, Patterson D, Leaning M. Evaluation of a decision support system for initiation and control of oral anticoagulation in a randomised trial. BMF 1997;314:1252-5.

27 Besselar A, Meer M, Gerrits-Drabbe C. Therapeutic contol of oral anticoagulant treatment in the Netherlands. $A m \mathcal{f}$ Clin Pathol 1989;90:685-90. 